Vol. 1 No. 4 Oktober 2021 e-ISSN : 2774-6283 | p-ISSN : 2775-0019

\title{
PENGGUNAAN MEDIA PEMBELAJARAN TIGA DIMENSI DALAM MENINGKATKAN PEMAHAMAN KONSEP MATERI JARAK TITIK, GARIS, DAN BIDANG PESERTA DIDIK DI SMK
}

\author{
LILIS ROKHAYAH \\ SMKN 1 Bandung \\ Email : $\underline{\text { lisro65@gmail.com }}$
}

\begin{abstract}
ABSTRAK
Berdasarkan fenomena yang kita temui dalam Pembelajaran Matematika mulai dari Sekolah Dasar sampai dengan Sekolah Menengah Atas atau Sekolah Menengah Kejuruan masih belum memuaskan. Pembelajaran Matematika cenderung masih pada pencapaian target kurikulum atau buku yang digunakan sebagai buku wajib. Pembelajaran masih didominasi guru, dimana peserta didik lebih cenderung menerima pengetahuan yang diberikan guru tanpa proses pengolahan potensi yang telah ada. Pembelajaran kurang menekankan pada pemahaman akan materi yang dipelajari dan tidak dikaitkan dengan pengalaman nyata peserta didk. Dengan kata lain, pembelajaran matematika belum bermakna karena pembelajaran belum dikaitkan dengan skema yang telah dimiliki oleh peserta didik. Berdasarkan fenomena di atas, dilakukan penelitian tentang penggunaan media pembelajaran tiga dimensi dalam meningkatkan pemahaman konsep materi jarak titik, garis, dan bidang peserta didik kelas XII OTKP-2 SMK Negeri 1 Bandung tahun pelajaran 2021-2022. Penelitian ini merupakan penelitian tindakan kelas yang bertujuan untuk meningkatkan pemahaman konsep belajar matematika peserta didik dengan menggunakan media pembelajaran tiga dimensi pada materi jarak titik, garis, dan bidang di kelas XII OTKP-2 SMK Negeri 1 Bandung tahun pelajaran 2021-2022. Setiap peserta didik dapat menggunakan media pembelajaran tiga dimensi ini sesuai dengan minat, dan potensi yang dimilikinya. Karena media pembelajaran yang digunakan adalah hasil dari buatan peserta didik sendiri, artinya media pembelajaran ini akan lebih dipahami oleh peserta didik dan lebih tertarik.
\end{abstract}

Kata Kunci: Media Pembelajaran, peserta didik

Based on the phenomenon that we encounter in Mathematics Learning from Primary School to Upper Secondary School or Vocational High School, it is still not satisfactory. Mathematics learning tends to still be at the achievement of curriculum targets or books used as compulsory books. Learning is still dominated by teachers, where learners are more likely to accept the knowledge provided by teachers without the process of processing the existing potential. Learning does not emphasize on the understanding of the material studied and is not associated with the actual experience of the participants. In other words, the learning of mathematics is not meaningful because the learning has not been associated with the scheme that has been possessed by learners. Based on the above phenomenon, research was conducted on the use of three-dimensional learning media in improving the understanding of the concept of point distance, line, and field of XII OTKP-2 students in SMK Negeri 1 Bandung academic year 2021-2022. This research is a classroom action research that aims to improve students' understanding of mathematics learning concepts by using three-dimensional learning media on the material of point distances, lines, and fields in XII OTKP-2 class SMK Negeri 1 Bandung academic year 2021-2022. Each learner can use this three -dimensional learning media in accordance with their interests, and potential. Because the learning media used is the result of the learners themselves, it means that this learning media will be better understood by learners and more interested.

Keywords: Learning Media, learners 


\section{PENDAHULUAN}

Seiring dengan majunya teknologi yang semakin canggih dan modern, mendorong kita sebagai pengajar harus mengikuti kemajuan ini mau tidak mau, suka tidak suka. Sebab kitapun dituntut untuk maju mengikuti seiring kemajuan. Oieh karenanya agar tidak ketinggalan, maka dituntut untuk menyajikan pengajaran yang menarik dan menyenangkan bagi peserta didik kita. Bagaimana tidak, sebab di SMK itu berbeda dengan SMA. Apa yang membedakannya, yaitu dari sumber dayanya itu sendiri, tingkat kecakapannya, ekonominya, dan masih ada faktor lainnya.

Di dalam pengajaran kita tidak boleh membedakan itu semua, sebab didalam undangundang sistem Pendidikan Nasional Nomor 20 tahun 2003 sudah dituangkan bahwa setiap manusia berhak atas pengajaran. Oleh karena itu pengajaran sebagai suatu proses merupakan suatu sistem yang melibatkan berbagai komponen. Komponen itu, antara lain komponen pendidik (guru), peserta didik (siswa), materi, sumber belajar, media pembelajaran, metode dan lain sebagainya. Komponen-komponen tersebut saling berinteraksi antar sesama komponen.

Keberhasilan pengajaran sangat ditentukan manakala pengajaran tersebut mampu mengubah diri peserta didik. Perubahan tersebut dalam arti dapat menumbuhkembangkan potensi-potensi yang dimiliki peserta didik. Sehingga peserta didik dapat memperoleh manfaatnya secara langsung dalam perkembangan pribadinya secara utuh. Tanggung jawab keberhasilan pengajaran tersebut berada di tangan seorang pendidik. Artinya, seorang guru harus berupaya semaksimal mungkin untuk mengatur proses pembelajaran sedemikian rupa sehingga komponen-komponen yang diperlukan dalam pengajaran tersebut dapat berinteraksi antar sesama komponen. Menurut CCSSO (Eggen, and Kauchak, 2012), Standar pengajaran dan pembelajaran efektif dikelompokkan ke dalam empat kategori umum, yaitu: 1. Pembelajar dan pembelajaran. Guru harus memahami peserta didik, perbedaan mereka, dan bagaimana mereka belajar. 2. Konten alias materi. Guru mesti memiliki pemahaman mendalam tentang materi yang mereka ajarkan dan bagaimana menjadikan materi itu dapat dipahami peserta didik. 3. Praktik mengajar. Guru harus memahami dan mengintegrasikan perencanaan, praktik mengajar, dan asesmen untuk mendorong pembelajaran bagi semua peserta didik. 4. Tanggung jawab profesional. Guru harus secara rutin memeriksa karya mereka sendiri lewat perenungan pribadi dan kerja sama dengan kolega.

Dalam proses belajar mengajar menurut Sudjarwo (1989), paling tidak ada 6 (enam) kejadian penting yang perlu ada dan perlu diperhatikan, yaitu: (1) Ciptakan dan jaga perhatian peserta didik, (2) keterkaitan pesan yang sedang diajarkan dengan pesan yang telah diterima sebelumnya. (3) Arahkan proses belajar mengajar dengan menggunakan bahan-bahan visual, audio, verbal dan kombinasi dari berbagai bahan tersebut. (4) ciptakan komunikasi 2 (dua) arah yang baik dan seimbang, sehingga umpan balik dari dan ke sasaran didik dapat dimanfaatkan untuk mempercepat tingkat kesamaan bahasa dan persepsi peserta didik. (5) Ciptakan dan pelihara kondisi untuk mengingat-ingat, menganalisis, menyimpulkan, menerapkan dan mengevaluasi pesan yang diterima peserta didik. (6) Selama dan setelah selesai belajar, sebaiknya dilakukan kegiatan evaluasi sesuai dengan tingkat formalitas masing-masing situasi belajar. Untuk menciptakan terjadinya 6 (enam) kejadian penting tersebut di atas, antara lain diperlukan media pembelajaran.

Menurut Gagne dan Briggs (dalam Azhar Arsyad, 2014:4) secara implisit mengatakan bahwa media pembelajaran meliputi alat yang secara fisik digunakan untuk menyampaikan isi materi pengajaran, yang terdiri antara lain buku, tape-recorder, kaset, video, camera, video recorder, film, slide (gambar bingkai), foto, gambar, grafik, televisi dan komputer. Sejalan dengan hal tersebut Munadi (2012) menyatakan bahwa "media merupakan segala sesuatu yang dapat menyampaikan dan menyalurkan pesan dari sumber secara terencana sehingga tercipta lingkungan belajar yang kondusif di mana penerimanya dapat melakukan proses belajar secara efisien dan efektif'. Dengan kata lain, media adalah komponen sumber belajar atau wahana fisik yang mengandung materi instruksional di lingkungan peserta didik yang dapat merangsang 
peserta didik untuk belajar. Dan juga merangsang peserta didik untuk belajar sesuai dengan minat dan bakat yang dimiliki.

Media pembelajaran seperti yang dimaksudkan oleh Gagne dan Briggs tersebut di atas, masih kurang digunakan oleh guru seperti misalnya di SMK Negeri 1 Bandung. Terutama di dalam proses belajar mengajar mata pelajaran matematika. Hal ini terbukti dari: (1) Pengakuan teman-teman guru, yang menyatakan kurangnya media pembelajaran matematika dan gaptek terhadap penggunaannya, (2) Guru masih menggunakan metode ceramah dalam proses belajar mengajar, meskipun dengan kurikulum 2013 dituntut dengan media pembelajaran, (3) Guru mengakui sulitnya mendapatkan dan membuat media pembelajaran matematika, (4) Masih kurang beragamnya media pembelajaran untuk matemataika.

Dengan adanya masalah-masalah tersebut di atas, maka berdasarkan hasil pengamatan sementara dapat disimpulkan, bahwa dalam proses belajar mengajar di SMK Negeri 1 Bandung khususnya di kelas XII tentang penggunaan media pembelajaran dimensi tiga dapat mengaktifkan konsep materi jarak titik, garis, dan bidang sebagai berikut: (1) Kurangnya minat peserta didik terhadap pengajaran matematika, (2) Peserta didik kurang aktif dalam proses belajar mengajar, (3) Sedikit terjadinya pembelajaran yang menyenangkan, (4) Tidak terdapat pembelajaran yang kreatif, (5) Matematika masih dianggap pelajaran yang sulit terutama dalam konsep Dimensi Tiga tentang materi Jarak Titik, Garis, dan Bidang.

Menurut para ahli dimensi merupakan kata yang sudah tidak asing lagi bagi sebagian besar orang. Dalam pembelajaran matematika dikenal dengan: 1. Bangun datar atau dua dimensi yang memiliki ukuran panjang dan lebar seperti bujur sangkar, persegi panjang, trapesium, segitiga, dan lain-lain. 2. Bangun ruang atau tiga dimensi yang memiliki ukuran panjang, lebar, dan tinggi seperti balok, kubus, bola, tabung, kerucut, dan lain-lain. Sementara menurut Sudjana (2011:101) pengertian media tiga dimensi adalah suatu alat peraga yang mempunyai panjang, lebar, serta tinggi dan dapat diamanati dari sudut pandang mana saja. Karena sudah memiliki ukuran kedalaman maka sesuatu yang digambarkan dalam dimensi tiga sudah memiliki volume atau isi. Dalam gambarannya di kenal dengan istilah tiga sumbu, yaitu sumbu $\mathrm{x}, \mathrm{y}$, dan z menyatakan panjang, lebar, dan tinggi.

Untuk mengatasi permasalahan yang ditemukan di atas, maka usaha yang akan ditempuh adalah dengan menggunakan media pembelajaran dalam proses pembelajarannya agar menarik dan dapat meningkatkan pemahaman peserta didik dalam belajarnya. Dengan harapan meningkatkan pemahaman dan penerapan pada peserta didik agar dapat mengubah anggapan bahwa pelajaran matematika merupakan pelajaran yang sulit menjadi pelajaran yang menyenangkan dan mengasikan. Sehingga harapan akan terjadi Pembelajaran Aktif, Kreatif, Efektif dan Menyenangkan (PAKEM) dalam belajarnya media pembelajaran adalah salah satu penunjang akan kebehasilan pembelajaran matematika. Maka penggunaan media pembelajaran harus disesuaikan dengan kebutuhan, situasi, dan kondisi peserta didik. Dengan kata lain suatu media pembelajaran tidak harus dinilai dari kecanggihan, tetapi dinilai dari fungsi dan perannya.

Bertolak dari uraian diatas, maka penulis tergerak untuk melakukan penelitian dengan mengangkat judul "Penggunaan Media Pembelajaran Tiga Dimensi Dalam Meningkatkan Pemahaman Konsep Materi Jarak, Titik, Garis, Dan Bidang Peserta Didik SMK"

\section{METODE PENELITIAN}

Penelitian tindakan kelas ini dilaksanakan di SMK Negeri 1 Bandung untuk mata pelajaran metamatika, dimulai bulan Juli 2021 sampai Agustus 2021. Sebagai subjek penelitian ini adalah kelas XII AP-2 Tahun Pelajaran 2021/2022 dengan jumlah peserta didik sebanyak 32 orang, terdiri dari 2 peserta didik laki-laki dan 30 peserta didik perempuan. Materi yang disajikan adalah penggunaan media pembelajaran tiga dimensi dalam meningkatkan pemahaman konsep materi jarak, titik, garis, dan bidang.

Prosedur Penelitian Tindakan Kelas ini direncanakan pelaksanaannya dalam 2 (dua) siklus secara berkelanjutan dalam 1 (satu) semester. Masing-masing siklus dilaksanakan dengan 
langkah-langkah: (1) Perencanaan tindakan, (2) Pelaksanaan tindakan, (3) Pengamatan (Observasi), dan (4) Refleksi. Secara rinci prosedur penelitian dijabarkan sebagai berikut:

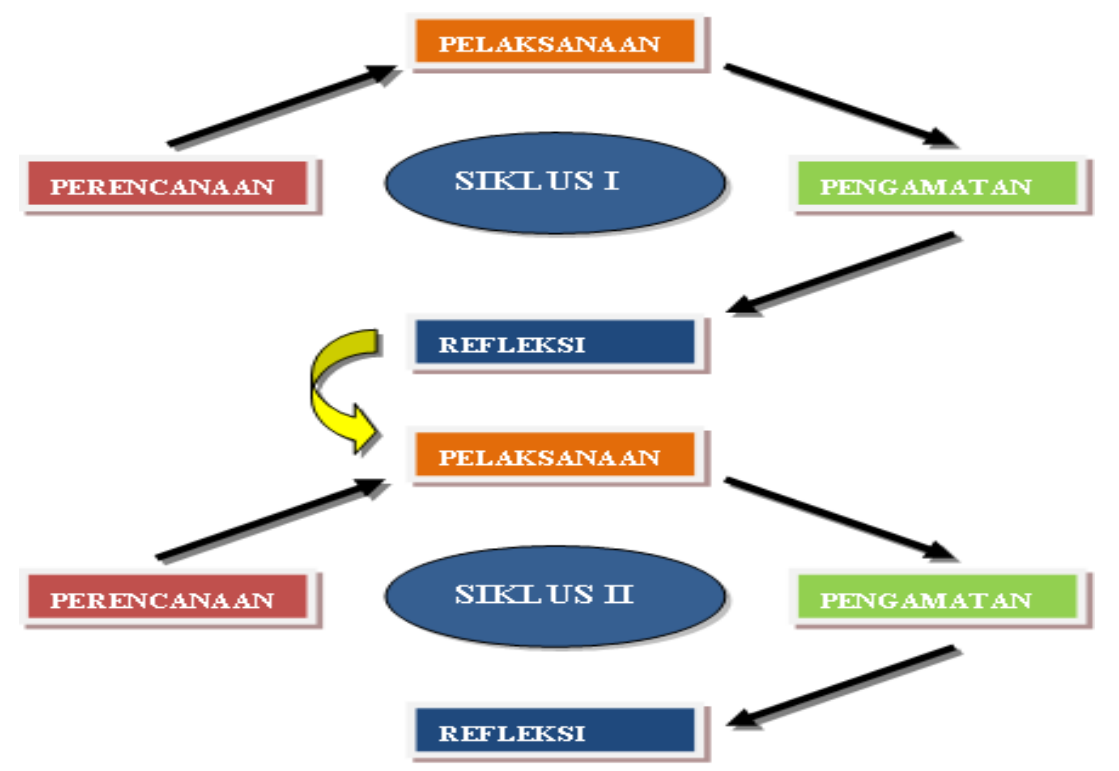

\section{Gambar 1. Skema Penelitian Tindakan Kelas}

Sebelum melaksanakan PTK seorang guru hendaknya mempersiapkan terlebih dahulu konsepnya dengan membuat perencanaan dalam bentuk tulisan. Arikunto (2010: 17) mengemukakan bahwa perencanaan adalah langkah yang dilakukan oleh guru ketika akan memulai tindakan. Maka persiapan yang dilakukan sebelum pelaksanaan tindakannya. adalah sebagai berikut: (1) Menyusun Rencana Pembelajaran tentang jarak titik, garis, dan bidang. (2) Membuat dan mengumpulkan media pembelajaran yang akan digunakan dalam proses belajar mengajar tentang jarak titik, garis, dan bidang. (3) Membuat Lembar Kerja Peserta Didik (LKPD) dan menyusun petunjuk Lembar Kerja Peserta Didik yang akan dilaksanakan dalam diskusi kelompok yang terdiri 4 orang dalam satu kelompok. (4) Menyiapkan format pengamatan dalam proses belajar mengajar tentang keaktifan peserta didik dalam diskusi kelompok.

Hasil pengamatan yang diperoleh selama proses belajar mengajar berlangsung dianalisa. Berdasarkan hasil analisa ini, guru dan kolaborator melakukan refleksi diri untuk menentukan keberhasilan penelitian.

\section{HASIL DAN PEMBAHASAN}

\section{Hasil}

Penelitian ini dilakukan sebanyak 2 siklus, setiap siklus menggambarkan kegiatan dan penguasaan materi yang terjadi pada kegiatan pembelajaran matematika dengan menggunakan media pembelajaran. Untuk melihat sejauh mana keaktifan peserta didik maka peneliti menggunakan range :
a. $75-100$ : sangat aktif
b. $55-74:$ aktif
c. $35-54$ : cukup aktiF
d. $0-34$ : kurang aktif

Dan melihat sejauh mana penguasaan materi oleh peserta didik dari hasil tes dengan acuan Kriteria Ketuntasan Belajar Minimal (KKM) yaitu 75. Adapun hasil penelitian dapat dilihat pada aktifitas peserta didik dan guru dalam uraian dengan ketercapaiannya sebagai berikut: 
Siklus 1

Tabel 1. Aktifitas Pembelajaran peserta didik dalam PBM

\begin{tabular}{|c|l|c|c|}
\hline \multirow{2}{*}{ No } & \multicolumn{1}{|c|}{$\begin{array}{c}\text { Aktifitas Peserta didik yang } \\
\text { Diobservasi }\end{array}$} & \multicolumn{2}{c|}{ Siklus } \\
\cline { 2 - 4 } 1 & $\begin{array}{l}\text { Menjawab pertanyaan atas pertanyan } \\
\text { apersepsi }\end{array}$ & 21 & 65,63 \\
\hline 2 & $\begin{array}{l}\text { Memberi tanggapan/ ide awal atas } \\
\text { permasalahan }\end{array}$ & 19 & 59,34 \\
\hline 3 & $\begin{array}{l}\text { Melakukan diskusi pemecahan } \\
\text { masalah }\end{array}$ & 30 & 93,75 \\
\hline 4 & Berdiskusi kelompok kecil & 20 & 62,50 \\
\hline 5 & $\begin{array}{l}\text { Mempresentasikan penyelesaian soal } \\
\text { Memberikan kesimpulan pertanyaan di akhir }\end{array}$ & 19 & 59,34 \\
\hline 7 & $\begin{array}{l}\text { Mengajukan pan } \\
\text { pembelajaran }\end{array}$ & 87,50 \\
\hline \multicolumn{1}{|c|}{ Rata-rata dalam \% } & 59,34 \\
\hline
\end{tabular}

Berdasarkan tabel 1, diakhir pembelajaran menggambarkan keterlibatan dan kualitas peserta didik. Hasil penelitian pada siklus pertama ini dari 7 aspek yang diobservasi di peroleh rata-rata $69,62 \%$ maka dapat disimpulkan bahwa proses pembelajaran matematika dengan menggunakan media pembelajaran, peserta didik cukup aktif mengikutinya.

Tabel 2. Penguasaan Materi Pembelajaran

\begin{tabular}{|c|l|c|l|}
\hline No & \multicolumn{1}{|c|}{ Nama } & Nilai & Keterangan \\
\hline 1 & AMANDA AYUDIA & 30 & $\begin{array}{l}\text { Belum } \\
\text { Tuntas }\end{array}$ \\
\hline 2 & AMEILIA SELVIANA & 60 & $\begin{array}{l}\text { Belum } \\
\text { Tuntas }\end{array}$ \\
\hline 3 & ANINDA AMALIA & 80 & Tuntas \\
\hline 4 & ANNISA MULYA & 78 & Tuntas \\
\hline 5 & CHITRA NUR AIINA LESTARI & 72 & $\begin{array}{l}\text { Belum } \\
\text { Tuntas }\end{array}$ \\
\hline 6 & DEWI SAPITRI & 80 & Tuntas \\
\hline 7 & DINI RIDZKIAWATI & 96 & Tuntas \\
\hline 8 & ERLIN DWI OKTAVIANI & 50 & $\begin{array}{l}\text { Belum } \\
\text { Tuntas }\end{array}$ \\
\hline 9 & GALANG ARIFA INDRAWAN & 85 & Tuntas \\
\hline 10 & $\begin{array}{l}\text { GELLAURA ALMUNAWAROH } \\
\text { SUTISNA }\end{array}$ & 50 & $\begin{array}{l}\text { Belum } \\
\text { Tuntas }\end{array}$ \\
\hline 11 & GHEA ERSA & 85 & Tuntas \\
\hline 12 & HANNA ZHOHRINAL HAQ & 40 & $\begin{array}{l}\text { Belum } \\
\text { Tuntas }\end{array}$ \\
\hline 13 & IVAN IRWANDI & 80 & Tuntas \\
\hline 14 & LASYA SEPTI FAUZIA & 30 & $\begin{array}{l}\text { Belum } \\
\text { Tuntas }\end{array}$ \\
\hline 15 & $\begin{array}{l}\text { MAHDIYYAH SALMA } \\
\text { RAFIDAH }\end{array}$ & 78 & $\begin{array}{l}\text { Tuntas } \\
\text { Tuntas }\end{array}$ \\
\hline 16 & MARSYA NUR FADILAH & $\begin{array}{l}\text { MUHAMAD DEZAN } \\
\text { RAMADHAN }\end{array}$ & Tuntas \\
\hline
\end{tabular}


Vol. 1 No. 4 Oktober 2021 e-ISSN : 2774-6283 | p-ISSN : 2775-0019

\begin{tabular}{|c|c|c|c|}
\hline 18 & NAJAH RAZI ARWIYANI & 68 & $\begin{array}{l}\text { Belum } \\
\text { Tuntas }\end{array}$ \\
\hline 19 & NASYWA AULIA FADILAH & 77 & Tuntas \\
\hline 20 & NAZILA LAILA KAROMAH & 70 & $\begin{array}{l}\text { Belum } \\
\text { Tuntas }\end{array}$ \\
\hline 21 & PUJA RAI SALSADIVA & 60 & $\begin{array}{l}\text { Belum } \\
\text { Tuntas }\end{array}$ \\
\hline 22 & $\begin{array}{l}\text { PUTRI FATMAWATI } \\
\text { KOSWARA }\end{array}$ & 40 & $\begin{array}{l}\text { Belum } \\
\text { Tuntas }\end{array}$ \\
\hline 23 & RAISYA ZAHRA SETIANI & 83 & $\begin{array}{l}\text { Belum } \\
\text { Tuntas }\end{array}$ \\
\hline 24 & RANI RAHMAN & 70 & $\begin{array}{l}\text { Belum } \\
\text { Tuntas }\end{array}$ \\
\hline 25 & SILVYANTI & 40 & $\begin{array}{l}\text { Belum } \\
\text { Tuntas }\end{array}$ \\
\hline 26 & SYEPHIA NUR FITRI & 50 & $\begin{array}{l}\text { Belum } \\
\text { Tuntas }\end{array}$ \\
\hline 27 & SYIFA RAHADATUL AISY & 35 & $\begin{array}{l}\text { Belum } \\
\text { Tuntas }\end{array}$ \\
\hline 28 & VINA ANGGRAENI & 40 & $\begin{array}{l}\text { Belum } \\
\text { Tuntas }\end{array}$ \\
\hline 29 & $\begin{array}{l}\text { WAHYUNI ELIZABETH } \\
\text { PUTRI }\end{array}$ & 80 & Tuntas \\
\hline 30 & YOLANDA HESTY AGUSTIN & 88 & Tuntas \\
\hline 31 & TASYA PUTRI SOPANDI & 78 & Tuntas \\
\hline 32 & $\begin{array}{l}\text { WINDIANTIKA SUGIHA } \\
\text { PUTRI }\end{array}$ & 95 & Tuntas \\
\hline & Rata-rata dalam \% & 65,41 & \\
\hline
\end{tabular}

Berdasarkan tabel 2, dapat disimpulkan bahwa proses pembelajaran matematika dengan menggunakan media pembelajaran peserta didik belum bisa mengikutinya dengan baik. Dari data diatas mengambarkan bahwa peserta didik yang tuntas hanya $65,41 \%$. Tetapi belum memenuhi syarat sesuai dengan yang diharapkan, yaitu memenuhi KKM 75. Walaupun pada tabel diatas menunjukan bahwa peserta didik cukup aktif dalam pembelajaran, namun ketuntasan peserta didik dalam menguasai materi pelajaran sebagai besar masih belum tuntas karena yang masuk katagori tuntas baru $65,41 \%$.

Hasil tanggapan dari peserta didik menyatakan bahwa pada pembelajaran, peserta didik lebih asyik memperhatikan slide materi dengan media pembelajaran tanpa memperhatikan konsep yang semestinya dikuasai peserta didik. Hal ini juga disadari guru bahwa selama pembelajaran guru terlalu memberikan kebebasan pada peserta didik untuk mengopersikan media pembelajaran lain yaitu komputer.

Siklus 2

Tabel 3. Aktifitas Pembelajaran peserta didik dalam PBM

\begin{tabular}{|c|l|c|c|}
\hline \multirow{2}{*}{$\begin{array}{c}\text { N } \\
\text { o }\end{array}$} & \multicolumn{1}{|c|}{$\begin{array}{c}\text { Aktifitas Peserta didik yang } \\
\text { Diobservasi }\end{array}$} & $\begin{array}{c}\text { Sre } \\
\text { k }\end{array}$ & $\%$ \\
\hline 1 & $\begin{array}{l}\text { Menjawab pertanyaan atas pertanyan } \\
\text { apersepsi }\end{array}$ & 27 & 84,38 \\
\hline 2 & $\begin{array}{l}\text { Memberi tanggapan / ide awal atas } \\
\text { permasalahan }\end{array}$ & 22 & 68,75 \\
\hline
\end{tabular}


Vol. 1 No. 4 Oktober 2021 e-ISSN : 2774-6283 | p-ISSN : 2775-0019

\begin{tabular}{|c|l|c|c|}
\hline 3 & Melakukan diskusi pemecahan masalah & 31 & 96,88 \\
\hline 4 & Berdiskusi kelompok kecil & 25 & 78,13 \\
\hline 5 & Mempresentasikan penyelesaian soal & 20 & 62,50 \\
\hline 6 & Memberikan kesimpulan & 28 & 87,50 \\
\hline 7 & $\begin{array}{l}\text { Mengajukan pertanyaan di akhir } \\
\text { pembelajaran }\end{array}$ & 22 & 68,75 \\
\hline \multicolumn{2}{|c|}{ Rata-rata dalam \% } & 78,13 \\
\hline
\end{tabular}

Berdasarkan tabel 3, hasil penelitian pada siklus kedua dari 7 aspek yang diobservasi diperoleh rata-rata $78,13 \%$ maka dapat disimpulkan bahwa proses pembelajaran menggunakan media pembelajaran menjadikan peserta didik aktif.

Tabel 4. Penguasaan Materi Pembelajaran

\begin{tabular}{|c|l|c|c|}
\hline $\begin{array}{c}\text { N } \\
\text { o }\end{array}$ & & $\begin{array}{c}\text { Nila } \\
\text { i }\end{array}$ & $\begin{array}{c}\text { Keterang } \\
\text { an }\end{array}$ \\
\hline 1 & AMANDA AYUDIA & 77 & Tuntas \\
\hline 2 & AMEILIA SELVIANA & 79 & Tuntas \\
\hline 3 & ANINDA AMALIA & 80 & Tuntas \\
\hline 4 & ANNISA MULYA & 78 & Tuntas \\
\hline 5 & CHITRA NUR AIINA LESTARI & 82 & Tuntas \\
\hline 6 & DEWI SAPITRI & 80 & Tuntas \\
\hline 7 & DINI RIDZKIAWATI & 96 & Tuntas \\
\hline 8 & ERLIN DWI OKTAVIANI & 77 & Tuntas \\
\hline 9 & GALANG ARIFA INDRAWAN & 85 & Tuntas \\
\hline 10 & GELLAURA ALMUNAWAROH & & \\
& SUTISNA & 79 & Tuntas \\
\hline 11 & GHEA ERSA & 85 & Tuntas \\
\hline 12 & HANNA ZHOHRINAL HAQ & 77 & Tuntas \\
\hline 13 & IVAN IRWANDI & 80 & Tuntas \\
\hline 14 & LASYA SEPTI FAUZIA & 75 & Tuntas \\
\hline 15 & MAHDIYYAH SALMA & & Tuntas \\
\hline 16 & MAFIDAH & 78 & \\
\hline 17 & MUHAMAD DEZAN & 75 & Tuntas \\
\hline 18 & NAJAH RAZI ARWIYANI & 77 & Tuntas \\
\hline 19 & NASYWA AULIA FADILAH & 77 & Tuntas \\
\hline 20 & NAZILA LAILA KAROMAH & 75 & Tuntas \\
\hline 21 & PUJA RAI SALSADIVA & 78 & Tuntas \\
\hline 22 & PUTRI FATMAWATI & 75 & Tuntas \\
\hline 23 & ROSWARA & 83 & Tuntas \\
\hline 24 & RANI RAHMAN & 75 & Tuntas \\
\hline 25 & SILVYANTI & 77 & Tuntas \\
\hline 26 & SYEPHIA NUR FITRI & Tuntas \\
\hline 27 & SYIFA RAHADATUL AISY & \\
\hline
\end{tabular}


Vol. 1 No. 4 Oktober 2021 e-ISSN : 2774-6283 | p-ISSN : 2775-0019

\begin{tabular}{|c|l|c|c|}
\hline 28 & VINA ANGGRAENI & 40 & $\begin{array}{c}\text { Belum } \\
\text { Tuntas }\end{array}$ \\
\hline 29 & $\begin{array}{l}\text { WAHYUNI ELIZABETH } \\
\text { PUTRI }\end{array}$ & 80 & Tuntas \\
\hline 30 & YOLANDA HESTY AGUSTIN & 88 & Tuntas \\
\hline 31 & TASYA PUTRI SOPANDI & 78 & Tuntas \\
\hline 32 & $\begin{array}{l}\text { WINDIANTIKA SUGIHA } \\
\text { PUTRI }\end{array}$ & 95 & Tuntas \\
\hline \multirow{2}{*}{ Jumlah } & $\begin{array}{c}2.50 \\
9\end{array}$ & \\
\hline & \multirow{2}{*}{ Rata-rata dalam \% } & $\mathbf{7 8 , 1}$ & \\
& & $\mathbf{4}$ & \\
\hline
\end{tabular}

Berdasarkan tabel 4, hasil penelitian pada siklus kedua ini dari hasil tes dapat disimpulkan bahwa proses pembelajaran matematika dengan menggunakan pembelajaran bisa mengikutinya dengan baik. Hal ini didapat dari nilai ketuntasan individu yang meningkat yaitu menjadi sebanyak 31 orang serta nilai ketuntasan klasikal juga mengalami peningkatan yaitu nilai rata rata sebesar $78,14 \%$. Maka dalam hal ini sudah memenuhi syarat sesuai dengan yang diharapkan, yaitu memenuhi KKM 75.

\section{Pembahasan}

Hasil yang diperoleh diatas bukanlah akhir dari sebuah pembelajaran, tetapi awal dari sebuah kemajuan dan kemauan untuk terus belajar dan berinovasi. Agar pembelajaran tidak ketinggalan oleh perkembangan modern, yaitu tidak gaptek teknologi. Maka dalam hal inilah guru dipacu untuk terus maju dan terus belajar agar tidak ketinggalan seiring kemajuan jaman. Menurut CCSSO (Eggen, and Kauchak, 2012), Standar pengajaran dan pembelajaran efektif dikelompokkan ke dalam empat kategori umum, yaitu: 1. Pembelajar dan pembelajaran. Guru harus memahami peserta didik, perbedaan mereka, dan bagaimana mereka belajar. 2. Konten alias materi. Guru mesti memiliki pemahaman mendalam tentang materi yang mereka ajarkan dan bagaimana menjadikan materi itu dapat dipahami peserta didik. 3. Praktik mengajar. Guru harus memahami dan mengintegrasikan perencanaan, praktik mengajar, dan asesmen untuk mendorong pembelajaran bagi semua peserta didik. 4. Tanggung jawab profesional. Guru harus secara rutin memeriksa karya mereka sendiri lewat perenungan pribadi dan kerja sama dengan kolega. Oleh karenanya, disini sebagai guru berusaha untuk meningkatkan pemahaman materi yang akan diajarkan yang dapat dimengerti peserta didik dengan bantuan media pembelajaran peserta didik paling tidak bisa mengikuti.

Nampak dari hasil yang diperoleh peserta didik kenaikkannya signifikan. Hasil penelitian pada siklus pertama ini dari 7 aspek yang diobservasi di peroleh rata-rata 69,62\% maka dapat disimpulkan bahwa proses pembelajaran matematika dengan menggunakan media pembelajaran, peserta didik cukup aktif mengikutinya. Sementara pada siklus kedua dari 7 aspek yang diobservasi diperoleh rata-rata 78,13\% maka dapat disimpulkan bahwa proses pembelajaran menggunakan media pembelajaran menjadikan peserta didik aktif. Paling tidak dengan penggunaan media pembelajaran membantu peserta didik pada proses pembelajarannya menjadi tertarik, sebagaimana tabel berikut:

Tabel 5. Aktifitas Pembelajaran peserta didik dalam PBM

\begin{tabular}{|c|c|c|}
\hline \multirow{2}{*}{ Aktifitas Peserta didik yang Diobservasi } & \multicolumn{2}{|c|}{ Siklus } \\
\cline { 2 - 3 } & $\mathbf{1}$ & $\mathbf{2}$ \\
\hline Rata-rata dalam \% & 69,62 & 78,13 \\
\hline
\end{tabular}




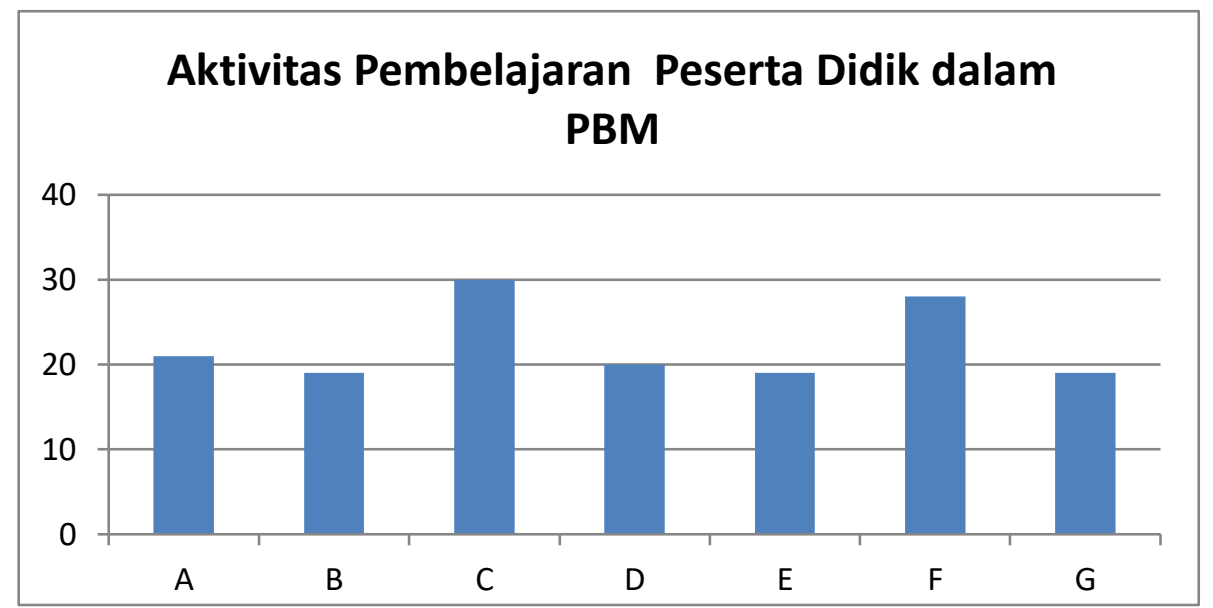

Gambar 2. Grafik Aktivitas Pembelajaran Peserta Didik Dalam PBM

Sementara pada penguasaan materi pembelajaran, siklus pertama ini dari hasil tes dapat disimpulkan bahwa proses pembelajaran matematika dengan menggunakan media pembelajaran peserta didik belum bisa mengikutinya dengan baik. Dari data mengambarkan bahwa peserta didik yang tuntas hanya $65,41 \%$, belum memenuhi syarat sesuai dengan yang diharapkan yaitu memenuhi KKM 75. Menunjukkan bahwa peserta didik cukup aktif dalam pembelajaran, dan penguasaan materi pelajaran sebagai besar masih belum tuntas. Dalam proses belajar mengajar menurut Sudjarwo (1989), paling tidak ada 6 (enam) kejadian penting yang perlu ada dan perlu diperhatikan, yaitu: (1) Ciptakan dan jaga perhatian peserta didik. (2) Tunjukkan keterkaitan pesan yang sedang diajarkan dengan pesan yang telah diterima sebelumnya. (3) Arahkan proses belajar mengajar dengan menggunakan bahan-bahan visual, audio, verbal dan kombinasi dari berbagai bahan tersebut. (4) Ciptakan komunikasi 2 (dua) arah yang baik dan seimbang, sehingga umpan balik dari dan ke sasaran didik dapat dimanfaatkan untuk mempercepat tingkat kesamaan bahasa dan persepsi peserta didik. (5) Ciptakan dan pelihara kondisi untuk mengingat-ingat, menganalisis, menyimpulkan, menerapkan dan mengevaluasi pesan yang diterima peserta didik. (6) Selama dan setelah selesai belajar, sebaiknya dilakukan kegiatan evaluasi sesuai dengan tingkat formalitas masing-masing situasi belajar.

Akan tetapi pada siklus kedua ini dari hasil tes dapat disimpulkan bahwa proses pembelajaran matematika dengan menggunakan media pembelajaran bisa mengikutinya dengan baik. Menurut Gagne dan Briggs (dalam Azhar Arsyad, 2014: 4) secara implisit mengatakan bahwa media pembelajaran meliputi alat yang secara fisik digunakan untuk menyampaikan isi materi pengajaran, yang terdiri antara lain buku, tape-recorder, kaset, video, camera, video recorder, film, slide (gambar bingkai), foto, gambar, grafik, televisi dan komputer. Sejalan dengan hal tersebut Munadi (2012) menyatakan bahwa "media merupakan segala sesuatu yang dapat menyampaikan dan menyalurkan pesan dari sumber secara terencana sehingga tercipta lingkungan belajar yang kondusif di mana penerimanya dapat melakukan proses belajar secara efisien dan efektif'. Dengan kata lain, media adalah komponen sumber belajar atau wahana fisik yang mengandung materi instruksional di lingkungan peserta didik yang dapat merangsang peserta didik untuk belajar. Dan juga merangsang peserta didik untuk belajar sesuai dengan minat dan bakat yang dimiliki.

Hamalik (1986) mengemukakan bahwa pemakaian media pengajaran dalam proses belajar mengajar dapat membangkitkan keinginan dan minat yang baru, membangkitkan motivasi dan rangsangan kegiatan belajar, dan bahkan membawa pengaruh-pengaruh psikologi terhadap peserta didik. Hal ini dapat dilihat dari nilai ketuntasan individu yang meningkat yaitu menjadi sebanyak 31 orang serta nilai ketuntasan klasikal juga mengalami peningkatan yaitu nilai rata rata sebesar $78,14 \%$. Maka dalam hal ini sudah memenuhi syarat sesuai dengan yang diharapkan, yaitu memenuhi KKM 75 sebagaimana tabel berikut: 
Tabel 6. Penguasaan Materi Pembelajaran

\begin{tabular}{|c|c|c|}
\hline \multirow{2}{*}{ Penguasaan Materi Pembelajaran } & \multicolumn{2}{|c|}{ Siklus } \\
\cline { 2 - 3 } & $\mathbf{1}$ & $\mathbf{2}$ \\
\hline Rata-rata dalam \% & 65,41 & 78,14 \\
\hline
\end{tabular}

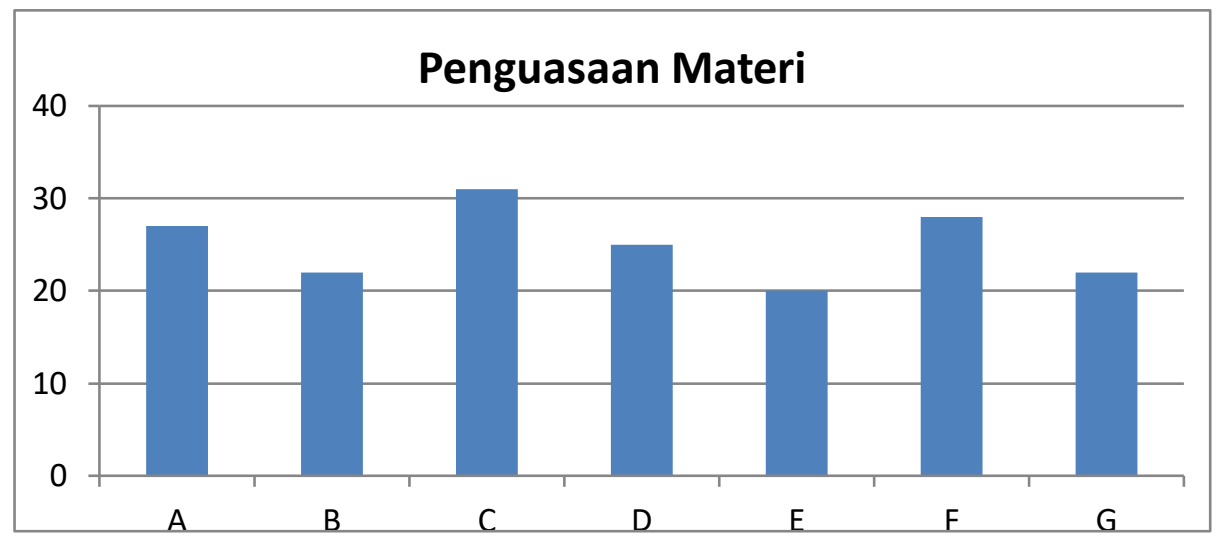

Gambar 3. Grafik Penguasaan Materi

\section{KESIMPULAN}

Penelitian Tindakan kelas tentang penggunaan media pembelajaran dimensi tiga dapat mengaktifkan peserta didik kelas XII AP-2 memahami konsep materi jarak titik, garis, dan bidang dalam proses belajar mengajar yang telah dilaksanakan dalam dua siklus menghasilkan kesimpulan sebagai berikut : Pada aktifitas peserta didik dapat kita lihat bahwa terjadi peningkatan dan perubahan yang signifikan dari siklus satu ke siklus selanjutnya hal ini dapat dilihat dari perolehan rata-rata yaitu; Siklus pertama dapat diidentifakasi dalam kategori cukup aktif $69,62 \%$ dengan nilai ketuntasan rata-rata belajar peserta didik $65,41 \%$. Siklus kedua aktif $78,13 \%$ dengan nilai ketuntasan rata-rata $78,14 \%$ dan peserta didik merasa senang belajar dengan menggunakan media pembelajaran.

Berdasarkan paparan hasil penelitian di atas, peneliti menyimpulkan bahwa pada siklus ke 1 peserta didik masih merasa canggung pembelajaran menggunakan media pembelajaran sedangkan pada siklus 2 peserta didik sudah mulai lancar. Hal ini dikarenakan peserta didik kelas XII AP-2 sudah paham akan kegunaan dari media pembelajaran, bahwa media pembelajaran itu sangat membatu dalam kegiatan belajar mengajar menjadi lebih menarik.

\section{DAFTAR PUSTAKA}

Abidin. (2014). Desain Sistem Pembelajaran Dalam Konteks Kurikulum 2013. Bandung: Refika Aditama

Arikunto, S. (2008). Dasar-dasar Evaluasi Pendidikan. Jakarta: Bumi Aksara. . (2016). Prosedur Penelitian: Suatu Pendekatan Praktik. Jakarta: Rineka Cipta

Arsyad, A. (2002). Media Pembelajaran. Jakarta: PT Raja Grafindo Persada. . (2013). Media Pembelajaran. Jakarta: Raja Grafindo Persada. (2014). Media Pembelajaran. Jakarta: Raja Grafindo Persada

Daryanto. (2015). Media Pembelajaran. Bandung: Sarana Tutorial Nurani

Dimyati dan Mudjiono. (2015). Belajar dan Pembelajaran. Jakarta: Rineka Cipta.

Hamalik. (2003). Media Pendidikan. Bandung: PT Citra Aditya Bakti Cipta.

(2016). Proses Belajar Mengajar. Jakarta: Bumi Aksara.

Hamdani. (2011). Strategi Belajar Mengajar. Bandung: Pustaka Setia

Huda. (2016). Pembelajaran Berbasis Multimedia dan Pembelajaran Konvensional. Jurnal Penelitian, Vol. 10, No.1, Februari 2016

Ibrahim, R. (2003). Perencanaan Pengajaran. Jakarta: Rineka Cipta 
Lubis, Effi Aswita. (2015). Strategi Belajar Mengajar. Medan: Perdana Publishing . (2015). Metodologi Penelitian Pendidikan. Bandung: Cita Pustaka Media

Mulyono, H. (2016). Using Quipper As Online Platform For Teaching and Learning English As A Foreign Languange. 16(1), 59-70, diperoleh dari http://www.tewtjorunal.org. Diakses tanggal 30 Mei 2017

Ngalim. (2014). Psikologi Pendidikan. Bandung: Remaja Rosdakarya

Rusman. (2013). Belajar dan Pembelajaran Berbasis Komputer. Bandung: Alfabeta

Sanaky, H. (2009). Media Pembelajaran. Yogyakarta. Safiri Insania Press

Sudjana dan Rivai. (2002). Media Pengajaran. Bandung: CV Sinar

Sudjana. (2009). Metode Statistika. Bandung: Transito

Sudjono. (2014). Pengantar Statistik Pendidikan. Jakarta: Rajawali Pers.

Sugiyono. (2014). Metode Penelitian Kuantitatif, Kualitatif, dan Kombinasi (Mixed Methods), Bandung: Alfabeta . (2014). Metode Penelitian Pendidikan Pendekatan Kuantitatif, Kualitatif dan R\&D. Bandung: Alfabeta . (2016). Metode Penelitian Kuantitatif, Kualitatif, dan $R \&$ D. Bandung : Alfabeta . (2017). Metode Penelitian Kuantitatif, Kualitatif dan R\&D. Bandung: Alfabeta

Sanjaya. (2008). Strategi Pembelajaran Berorientasi Standar Proses Pendidikan, Jakarta: Kencana Preada Media Grouf 